\title{
Clinical Significance of Early Changes in Circulating Tumor Cells from Patients Receiving First-Line Cisplatin-Based Chemotherapy for Metastatic Urothelial Carcinoma $^{1}$
}

\author{
Emanuela Fina $^{\mathrm{a}, 2}$, Andrea Necchi ${ }^{\mathrm{b}, 2, *}$, Patrizia Giannatempo $^{\mathrm{b}}$, Maurizio Colecchia $^{\mathrm{c}}$, \\ Daniele Raggi $^{\mathrm{b}}$, Maria Grazia Daidone ${ }^{\mathrm{a}, *}$ and Vera Cappelletti ${ }^{\mathrm{a}}$ \\ ${ }^{\mathrm{a}}$ Department of Experimental Oncology and Molecular Medicine, Fondazione IRCCS Istituto \\ Nazionale dei Tumori, Milan, Italy \\ ${ }^{\mathrm{b}}$ Department of Medical Oncology, Fondazione IRCCS Istituto Nazionale dei Tumori, Milan, Italy \\ ${ }^{\mathrm{c}}$ Department of Pathology and Laboratory Medicine, Fondazione IRCCS Istituto Nazionale dei Tumori, \\ Milan, Italy
}

\begin{abstract}
.
Background: The therapeutic paradigm of metastatic urothelial carcinoma (UC) is rapidly shifting and new biomarkers are needed to enhance patient selection.

Objective: Early identification of dynamic predictors of outcome may be a key to optimize the sequence of effective therapies in metastatic UC patients.

Methods: Blood samples from patients receiving first-line MVAC chemotherapy were collected at baseline $\left(\mathrm{T}_{0}\right)$ and after 2 cycles $\left(\mathrm{T}_{2}\right)$. Samples were processed by immunomagnetic beads (AdnaTest ProstateCancerSelect kit) and the expression of EPCAM, MUC1 and ERBB2 was studied using multiplex-PCR. Circulating tumor cell (CTC) positivity and cutoffs, obtained by receiver operator characteristic (ROC) curve analysis in healthy donors, were: $\geq 1$ positive marker among EPCAM $(\geq 0.40 \mathrm{ng} / \mu \mathrm{l}), M U C 1(\geq 0.10 \mathrm{ng} / \mu \mathrm{l})$ and ERBB2 $(\geq 0.20 \mathrm{ng} / \mu \mathrm{l})$. CTC variation $\left(\mathrm{T}_{0} / \mathrm{T}_{2}\right)$ was split in favorable $(+/-$, $-/-,-/+)$ and unfavorable groups (+/+). Cox regression analyses evaluated associations with clinical factors.

Results: In this pilot study to assess a new CTC detection method, among 31 evaluable patients, 17 (54.8\%) were CTC-positive at $\mathrm{T}_{0}$. No association was found between CTC and objective response to MVAC. CTC dynamic changes better predicted 3-year progression-free (PFS) and overall survival (OS) compared to CTC status assessed at single time points.
\end{abstract}

\footnotetext{
${ }^{1}$ Presented in poster session, 2016 annual meeting of the European Society for Medical Oncology (ESMO), 7-11 October 2016, Copenhagen, Denmark.

${ }^{2}$ Equal credit.

*Correspondence to: Andrea Necchi, Department of Medical Oncology, Fondazione IRCCS Istituto Nazionale dei Tumori, Via G. Venezian 1, 20133 Milan, Italy. Tel.: +39 022390 2402;
}

\footnotetext{
Fax: +39 022390 3150; E-mail: andrea.necchi@ istitutotumori. mi.it and Maria Grazia Daidone, Department of Experimental Oncology and Molecular Medicine, Fondazione IRCCS Istituto Nazionale dei Tumori, Via G. Venezian 1, 20133 Milan, Italy. Tel.: +39 022390 2238; Fax: +39 022390 2764; E-mail: mariagrazia.daidone@istitutotumori.mi.it.
} 
Unfavorable trend was univariably detrimental on 3 -year PFS ( $10 \%$ vs. $49.2 \%, p=0.006)$ and OS (20\% vs. $63.5 \%, p=0.017)$. Significance was maintained after controlling for liver metastases $(p=0.031$ and $p=0.025$ for PFS and OS) and MSKCC score $(p=0.014$ and 0.025$)$.

Conclusions: Newly described early CTC changes during chemotherapy might be useful to improve our prognostic ability. Pending validation, these results could fulfill the promise to help accelerating therapeutic sequences.

Keywords: Urothelial carcinoma, circulating tumor cells, first-line chemotherapy, prognostic factors

\section{INTRODUCTION}

The prognosis of patients with advanced urothelial carcinoma (UC) is frustratingly poor, owing to the negative results of several clinical trials that were aimed to improve the achievable outcomes with standard chemotherapy [1]. New advances with the use of immune checkpoint inhibitors are being made in this disease and atezolizumab, a monoclonal antibody targeting the programmed death-ligand 1 (PD-L1), was granted conditional approval in the post-platinum metastatic setting by the U.S. Food and Drug Administration (FDA) [2]. Similarly, promising results from another study with a PD-L1 antibody, durvalumab, have been presented [3], recognizing the fact that metastatic UC represents an area of enormous unmet medical need. Waiting for the results of clinical trials of immunotherapy in earlier disease stages, improvements in the administration of standard chemotherapy options as well as novel prognostic factors are warranted in the first-line setting. Thus far, the greatest improvement in the context of standard therapy would be to provide clinicians with tools to early change ineffective treatments and anticipate new drugs in these patients.

Circulating tumor cells (CTC) represent a useful blood-borne biomarker to monitor the disease course and their clinical validity has been well acknowledged in genitourinary cancers, especially in castration-resistant prostate cancer [4]. Both molecular and immunological approaches have been used to detect or enumerate CTCs in patients with superficial or metastatic UC. Urothelial and tumor-specific markers, such as cytokeratin-18, -19 and -20 , uroplakin II, epidermal growth factor receptor, mucin-7, tenascin- $\mathrm{C}$, survivin and human telomerase reverse transcriptase are detectable at the mRNA level in the blood cellular fraction of UC patients, yet their clinical significance has not been clarified [5-11]. Among the available methods, that were reviewed in a meta-analysis from 21 studies on more than 800 patients [12], CTC isolation using the CellSearch ${ }^{\circledR}$ assay (Janssen Diagnostics, Raritan, NJ) proved to be associated with metastatic tumor load [13-17], and provided clinically relevant results, particularly in patients with early stage disease [17-21]. Conversely, there is limited information regarding the role of CTCs in monitoring response and outcome of chemotherapy in patients with high-grade or advanced disease [17, 22, 23]. Moreover, methods based on EpCAM-dependent enrichment usually fail to enrich for CTCs with mesenchymal features, suggesting that implementation of capture systems with additional antibodies is required, and analysis of more than one molecular marker at the transcript level may increase the detection capability [24].

Here we report a single-center, prospective study on a population of UC patients receiving first-line chemotherapy for metastatic disease. In consideration of the small sample size it represents a pilot study aiming at evaluate the clinical validity of early CTC monitoring by using an original immunomagneticand PCR-based CTC detection approach in the metastatic context. Clinical validity of our CTC assay, which represents the primary objective of this study, was mainly investigated in terms of association with progression-free survival (PFS) and overall survival (OS).

\section{PATIENTS AND METHODS}

\section{Study design}

From July 2012 to May 2014, 31 patients received first-line methotrexate, vinblastine, doxorubicin and cisplatin (MVAC) chemotherapy for metastatic disease at the Fondazione IRCCS Istituto Nazionale dei Tumori, Milan. A flow chart including reason for patient exclusion is shown in Fig. 1. Blood aliquots were collected at baseline (i.e., at $\mathrm{T}_{0}$, the day before starting chemotherapy) and after the second cycle (at $\mathrm{T}_{2}$ ) together with the disease restaging as per Institutional policy. The second disease assessment was planned at the end of treatment (4 to 6 cycles of chemotherapy). Responses were assessed according to Response Evaluation Criteria in Solid Tumors 


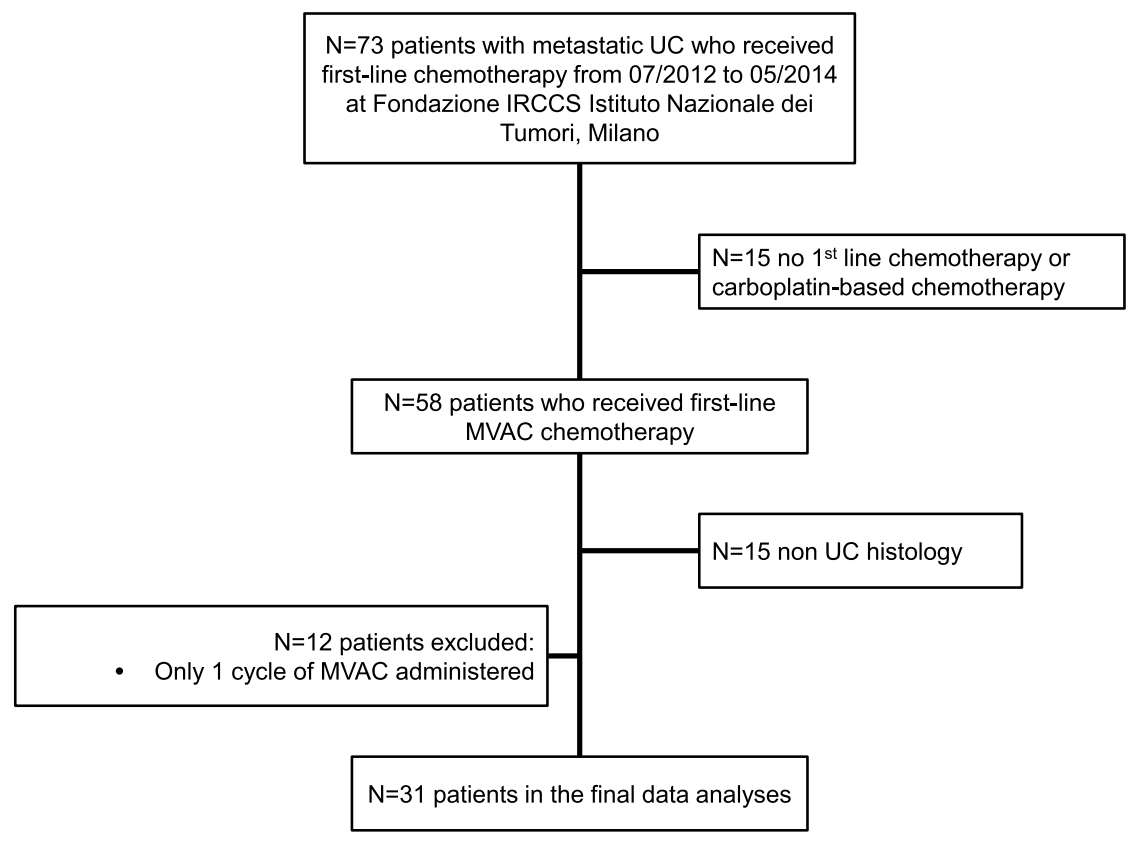

Fig. 1. Study flow chart, with counts and reasons for patient selection. Abbreviations: MVAC: methotrexate, vinblastine, doxorubicin, cisplatin chemotherapy; UC: urothelial carcinoma.

(RECIST), version 1.1 [25]. Close surveillance was applied in all cases who achieved at least a stable disease (SD), and computed tomography scans were repeated every 3 months in this phase.

The study was carried out after approval of the Institutional Review Board and Ethical Committee and written informed consent was obtained from all patients.

\section{Method of CTC assessment}

Samples of peripheral whole blood were collected in $\mathrm{K}_{3}$ EDTA BD Vacutainer tubes. CTC analysis was performed on an $8 \mathrm{~mL}$ sample obtained after withdrawal of the blood volumes (about $50 \mathrm{~mL}$ ) necessary for routine tests minimizing this way the risk of contamination with epithelial skin cells during puncture. Following the reporting recommendations for tumor marker prognostic studies (REMARK) [26], fresh samples were stored at $4{ }^{\circ} \mathrm{C}$ at dark and processed within 1 hour from withdrawal. Enrichment for CTCs was performed using the AdnaTest ProstateCancerSelect kit (AdnaGen, AG, Langenhagen, Germany). Briefly, $5 \mathrm{~mL}$ of whole blood were incubated with $100 \mu \mathrm{L}$ of magnetic beads coated with antibodies against the epithelial and tumor-associated antigens EpCAM and ErbB2. Cell-beads complexes were captured using the AdnaMag-L magnetic particle concentrator and cell lysates were stored at $-20{ }^{\circ} \mathrm{C}$ for up to 14 days before mRNA isolation and molecular analysis (AdnaTest BreastCancerDetect kit, AdnaGen).

The expression of EPCAM, MUC1 and ERBB2 epithelial and tumor-specific markers, co-amplified with $A C T B$ as control, was assessed by semiquantitative multiplex-PCR using the PrimerMix provided in the AdnaTest BreastCancerDetect kit.

The following values were used for each single gene: $\geq 0.40 \mathrm{ng} / \mu \mathrm{L}$ for EPCAM, $\geq 0.10 \mathrm{ng} / \mu \mathrm{L}$ for MUC1 and $\geq 0.20 \mathrm{ng} / \mu \mathrm{L}$ for ERBB2. Samples were called as CTC-positive if at least one of either EPCAM, MUC1 or ERBB2 marker level was above the cut-off value. Otherwise, they were defined as CTC-negative.

For quality control assessment, $A C T B$ concentration $\geq 3.0 \mathrm{ng} / \mu \mathrm{L}$ was established as a necessary criterion to consider a CTC sample as evaluable, on the basis of results obtained from healthy donors. Results from CTC test were collected and analyzed without knowledge of clinical data.

\section{Statistical analyses}

Patient, disease features, and outcome data were summarized using descriptive statistics with frequencies and percentages used for categorical variables 
and medians and inter-quartile range (IQR) for continuous variables. The associations between variables were assessed by Fisher and $\chi^{2}$ tests, with Yates' correction when appropriate. The primary objective of the analysis was to evaluate the prognostic role of either $T_{0}, T_{2}$, or $T_{0}-T_{2}$ CTC status and variation on PFS and OS. As this study was exploratory in nature, no formal statistical hypothesis was postulated, although the enrolled number of patients was consistent with the entropy-based approach to sample size in translational clinical trials as proposed by Piantadosi et al. [27]. Two-year minimum follow-up was allowed to have reliable survival data. Based on the hypothesis that CTC changes could better predict the outcome, samples were grouped according to CTC variation. Additionally, due to small numbers, CTC variation was arbitrarily split in favorable $(-/-,+/-$ and $-/+)$ and unfavorable $(+/+)$ groups using the positivity cut-offs and positivity criteria already described.

The Kaplan-Meier method was used for estimation of time-to-event outcomes such as PFS and OS. Cox proportional hazards regression was used to investigate the prognostic role of CTC status and variations, and of the other clinical-pathologic factors on PFS and OS, with relative hazard ratios (HR) and $95 \%$ confidence intervals $(\mathrm{CI})$, using the putative best prognosis category as a reference. Each selected factor was investigated in univariable analyses. Due to small numbers, bivariable analyses were performed to evaluate the independent prognostic impact of CTC trend after controlling for the following clinical factors: presence $v s$. absence of liver metastases, MSKCC score (1-2 vs. 0) [28], and RECIST response (progressive disease [PD] $v s$. complete response $[\mathrm{CR}]+$ partial response $[\mathrm{PR}]+\mathrm{SD})$. All tests (performed in SAS software, version 9.2) were two-sided and a $p$-value of $\leq 0.05$ was considered statistically significant.

\section{RESULTS}

\section{Patient characteristics}

Table 1 presents patient and tumor baseline characteristics. Median follow-up for censored patients was 27 months (IQR 12-35). Overall, median PFS and OS were 8 months (IQR 5-22) and 12 months (IQR $8-27)$, respectively. Twenty-one patients progressed and 16 died for disease progression after 3 years of follow-up.
Table 1

Patient and tumor characteristics at baseline

\begin{tabular}{|c|c|c|c|}
\hline Variable & $\begin{array}{c}\text { No of } \\
\text { patients }\end{array}$ & $\begin{array}{l}\text { No of CTC+ } \\
\text { patients }(\%)\end{array}$ & $p$-value \\
\hline All patients & 31 & $17(54.8)$ & \\
\hline \multicolumn{4}{|l|}{ Gender } \\
\hline Female & 9 & $5(55.6)$ & \multirow[t]{2}{*}{$1.0^{a}$} \\
\hline Male & 22 & $12(54.5)$ & \\
\hline \multicolumn{4}{|l|}{ Age } \\
\hline$<65$ & 13 & $5(38.5)$ & \multirow[t]{2}{*}{$0.23^{b}$} \\
\hline$\geq 65$ & 18 & $12(66.7)$ & \\
\hline \multicolumn{4}{|l|}{ Tumor primary site } \\
\hline Bladder & 26 & $13(50.0)$ & \multirow[t]{2}{*}{$0.35^{a}$} \\
\hline Upper tract & 5 & $4(80.0)$ & \\
\hline \multicolumn{4}{|l|}{ Metastatic sites } \\
\hline Lymph-nodes & 21 & $12(57.1)$ & \multirow[t]{3}{*}{$0.21^{c}$} \\
\hline Liver-Lung-Bone & 17 & $11(64.7)$ & \\
\hline Other* & 5 & $1(20.0)$ & \\
\hline \multicolumn{4}{|l|}{ Histology } \\
\hline Pure UC & 24 & $14(58.3)$ & \multirow[t]{2}{*}{$0.47^{c}$} \\
\hline Other & 7 & $3(42.9)$ & \\
\hline \multicolumn{4}{|l|}{ Smoking status $§$} \\
\hline Never smoker & 9 & $3(33.3)$ & \multirow[t]{3}{*}{$0.11^{d}$} \\
\hline Former smoker & 11 & $5(45.5)$ & \\
\hline Current smoker & 9 & $7(77.8)$ & \\
\hline \multicolumn{4}{|l|}{ MSKCC score } \\
\hline 0 & 15 & $7(46.7)$ & \multirow[t]{3}{*}{$0.38^{e}$} \\
\hline 1 & 10 & $6(60.0)$ & \\
\hline 2 & 6 & $4(66.7)$ & \\
\hline
\end{tabular}

Abbreviations: CTC: circulating tumor cell; UC: urothelial carcinoma. ${ }^{\ddagger}$ One patient had disease in both sites. ${ }^{*}$ Peritoneum, soft tissue, pleura, brain. ${ }^{\complement}$ The analyses involved $29 / 31$ patients as data

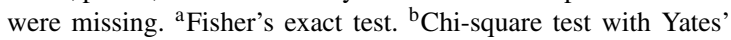
correction. ${ }^{\mathrm{c}}$ Chi-square test. ${ }^{\mathrm{d}}$ Fisher's exact test, Never+Former smokers vs. Current smokers. ${ }^{\mathrm{e}}$ Chi-square test, 0 vs. $1+2$

At $\mathrm{T}_{0}$ 17/31 (54.8\%) patients were CTC-positive. No clinical or histopathological characteristics were associated with baseline CTC status (Table 1). CTC positivity at $\mathrm{T}_{2}$ was obtained in 17/26 (65.4\%) evaluable patients. $M U C l$ was the most frequently detected marker among CTC-positive samples both at $\mathrm{T}_{0}$ $(76.5 \%)$ and at $\mathrm{T}_{2}(88.2 \%)$, whereas EPCAM contribute to CTC positivity was $64.7 \%$ at $\mathrm{T}_{0}$ and $70.6 \%$ at $\mathrm{T}_{2}$. Co-expression of EPCAM and MUCl was observed in $17.6 \%$ and $58.8 \%$ of CTC-positive samples at $\mathrm{T}_{0}$ and $\mathrm{T}_{2}$, respectively, while $E R B B 2$ was detected in $41.2 \%$ of CTC-positive samples at $\mathrm{T}_{0}$ and never at $\mathrm{T}_{2}$. Baseline co-expression of the three investigated markers was found in $29.4 \%$ of CTC-positive samples (Supplementary Table 1).

\section{Association of CTC status and CTC changes with response and outcome}

CTC status, evaluated at $T_{0}$ or $T_{2}$ time-points or as CTC trend (defined as CTC status variation between 
$\mathrm{T}_{0}$ and $\mathrm{T}_{2}$ and categorized as $-/-,+/-$ and $-/+v s$. $+/+$ ), was not significantly associated with RECIST response, either categorized as $\mathrm{CR}+\mathrm{PR}+\mathrm{SD}$ vs. $\mathrm{PD}$, $\mathrm{CR}$ vs. $\mathrm{PR}+\mathrm{SD}$ vs. $\mathrm{PD}$ or $\mathrm{CR}+\mathrm{PR}$ vs. $\mathrm{SD}+\mathrm{PD}$.

Results of univariable analyses of 3-year PFS and OS are shown in Table 2. Presence of liver metastases, MSKCC score, and clinical response were significantly associated to PFS and OS. PFS and OS were higher in CTC-positive patients, both at $\mathrm{T}_{0}$ and at $\mathrm{T}_{1}$, compared to CTC-negative ones $\left(\mathrm{T}_{0}: 50.0 \%\right.$ vs. $17.6 \%, \mathrm{~T}_{2}: 44.4 \%$ vs. $29.4 \%$ and $\mathrm{T}_{0}: 57.1 \%$ vs. $28.8 \%, \mathrm{~T}_{2}: 59.3 \%$ vs. $41.2 \%$, for PFS and OS, respectively). However, categorization of patients according to CTC evaluated at $\mathrm{T}_{0}$ and $\mathrm{T}_{2}$ was not prognostic, whereas an association with PFS (HR: 5.04, 95\%CI: 1.58-16.05, $p=0.006$, Fig. 2A) and OS (HR: 3.97, 95\% CI: $1.27-12.38, p=0.017$, Fig. 2B) was observed after splitting patients according to CTC trend. In patients with persistent CTC-positive status (unfavorable CTC trend) the median PFS was 6 months, remarkably shorter compared to patients with favorable CTC trend (20 months). Median OS of the former was 8 months whereas more than $65 \%$ of patients with favorable CTC was alive at 3 years. In addition, PFS and OS were analyzed as a function of CTC trend in the response subsets (Supplementary Table 2). Patients with CR to chemotherapy showed higher PFS and OS probabilities in the group with favorable CTC trend compared to the unfavorable one (100\% vs. 33\%, respectively, for both PFS and OS), while those with PR or SD had shorter PFS when CTC status was persistently positive compared to cases with favorable trend ( $42 \% v s .0 \%, p=0.023$ ).

Results of Cox bivariable analyses are shown in Table 3. CTC trend was still prognostic for PFS and OS after adjusting for liver metastases $(p$-value $=0.0314$ and 0.0255 , respectively $)$ and MSKCC score $(p$-value $=0.014$ and 0.025 , respectively). After controlling for response, CTC trend was prognostic for PFS (HR: 2.95, 95\% CI: 1.02-8.56, $p=0.046$ ) but not for OS (HR: 2.84, 95\% CI: $0.80-10.07, p=0.106)$. On the other side, adjustment for CTC trend maintained the statistical significance of MSKCC (HR: $3.19 ; 95 \%$ CI: $1.12-9.10 ; p=0.031$ ) and response (HR: 47.47; 95\% CI: 3.77-597.85; $p=0.003$ ) on PFS, whereas the prognostic significance on OS was maintained as a trend for MSKCC only (HR: $3.20 ; 95 \%$ CI: $1.00-10.28 ; p=0.051$ ).

\section{DISCUSSION}

The present pilot study was designed to evaluate the feasibility of an immunoenrichment method for

Table 2

Univariable analyses of 3-year progression-free and overall survival

\begin{tabular}{|c|c|c|c|c|c|c|c|}
\hline \multirow[t]{2}{*}{$\overline{\text { Variable }}$} & \multirow[t]{2}{*}{$\mathrm{N}$} & \multicolumn{3}{|c|}{ PFS } & \multicolumn{3}{|c|}{ OS } \\
\hline & & $\begin{array}{c}\text { PFS } \\
\text { probability } \\
(\%)\end{array}$ & HR 95\% CI & $P$ & $\begin{array}{c}\text { OS } \\
\text { probability } \\
(\%)\end{array}$ & HR 95\% CI & $P$ \\
\hline \multicolumn{8}{|l|}{$\overline{\text { CTC status at } \mathrm{T}_{0}}$} \\
\hline Negative* & 14 & 50.0 & & & 57.1 & & \\
\hline Positive & 17 & 17.6 & $1.87(0.75-4.65)$ & 0.18 & 28.8 & $1.72(0.62-4.74)$ & 0.30 \\
\hline \multicolumn{8}{|l|}{ CTC status at $\mathrm{T}_{2}$} \\
\hline Negative* & 9 & 44.4 & & & 59.3 & & \\
\hline Positive & 17 & 29.4 & $1.75(0.61-4.92)$ & 0.31 & 41.2 & $2.03(0.56-7.44)$ & 0.28 \\
\hline \multicolumn{8}{|l|}{ CTC variation $\mathrm{T}_{0}-\mathrm{T}_{2}$} \\
\hline Negative-negative* & 4 & 50.0 & - & - & 50.0 & - & - \\
\hline Positive-negative & 5 & 40.0 & $0.99(0.17-5.94)$ & 0.99 & 66.7 & $0.41(0.037-4.55)$ & 0.47 \\
\hline Negative-positive & 7 & 57.1 & $0.80(0.13-4.82)$ & 0.81 & 71.4 & $0.52(0.074-3.73)$ & 0.52 \\
\hline Positive-positive & 10 & 10.0 & $2.85(0.61-13.37)$ & 0.18 & 20.0 & $2.41(0.50-11.52)$ & 0.27 \\
\hline \multicolumn{8}{|l|}{ Liver metastases } \\
\hline Negative* & 26 & 37.6 & & & 46.4 & & \\
\hline Positive & 5 & 0 & $3.37(1.19-9.56)$ & 0.022 & 26.7 & $4.62(1.13-18.95)$ & 0.033 \\
\hline \multicolumn{8}{|l|}{ MSKCC score } \\
\hline $0^{*}$ & 15 & 45.7 & & & 57.1 & & \\
\hline $1+2$ & 16 & 18.7 & $2.55(1.04-6.27)$ & 0.040 & 26.5 & $2.88(1.03-8.14)$ & 0.045 \\
\hline \multicolumn{8}{|l|}{ RECIST response } \\
\hline $\mathrm{CR}+\mathrm{PR}+\mathrm{SD}^{*}$ & 22 & 35.8 & & & 49.4 & & \\
\hline $\mathrm{PD}$ & 5 & 0 & $55.27(6.06-504.37)$ & 0.0004 & 0 & $5.30(1.57-17.92)$ & 0.007 \\
\hline
\end{tabular}

Abbreviations: CI: confidence interval; CR: complete response; CTC: circulating tumor cell; HR: hazard ratio; OS: overall survival; PD: progressive disease; PFS: progression-free survival; PR: partial response; RECIST: Response Evaluation Criteria in Solid Tumors; SD: stable disease. * Reference category. 

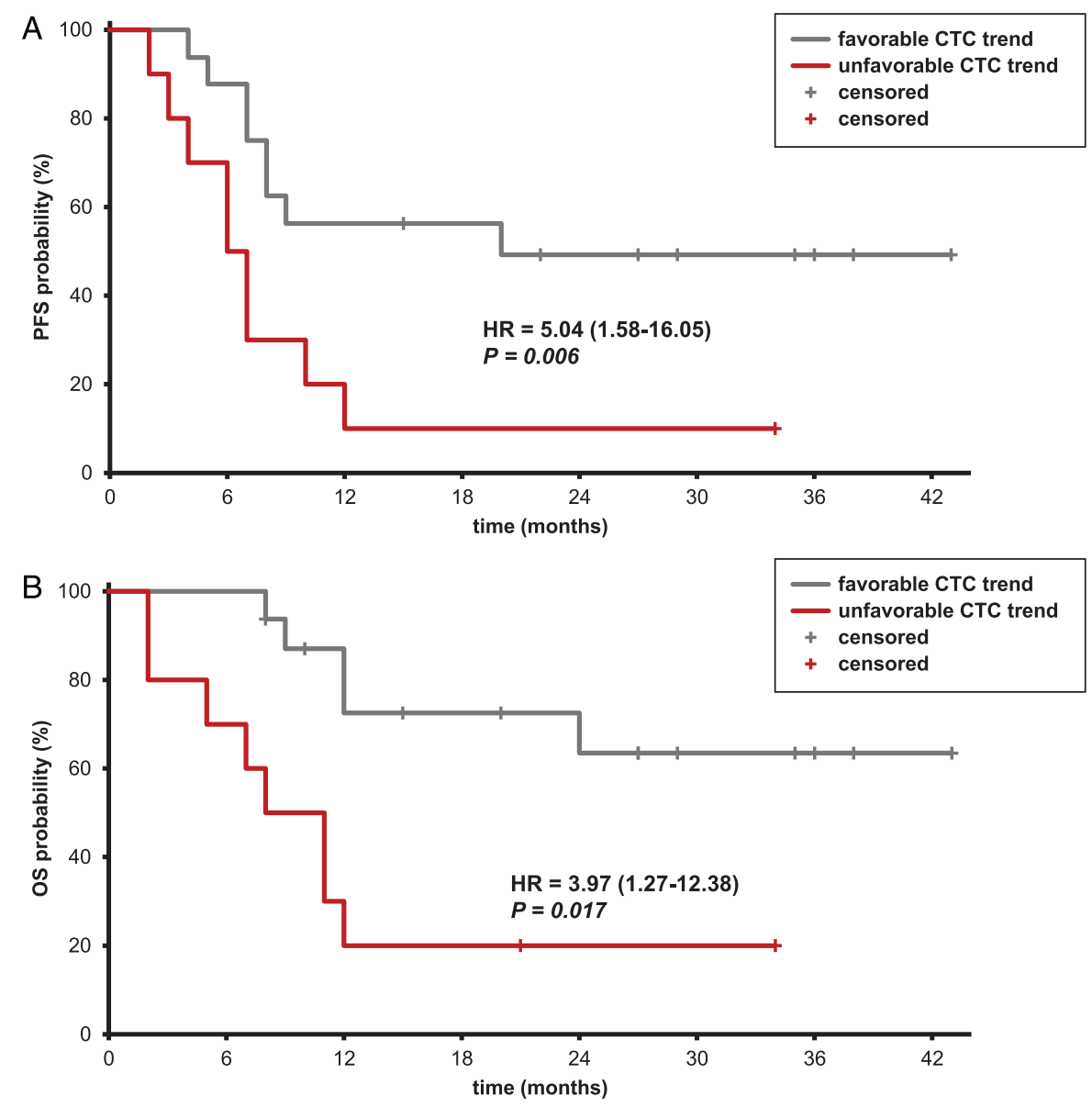

Fig. 2. Kaplan-Meier curves of progression-free (A) and overall survival (B) according to CTC trend after the first 2 cycles of chemotherapy. Legend: light grey line: favorable CTC trend; dark grey line: unfavorable CTC trend. Abbreviations: CTC: circulating tumor cells; HR: hazard ratio; CI: confidence interval; OS: overall survival; PFS: progression-free survival.

Table 3

Bivariable analysis of 3-year progression-free and overall survival as a function of CTC trend

\begin{tabular}{|c|c|c|c|c|c|c|c|c|c|c|c|c|}
\hline \multirow[t]{2}{*}{ Variable } & \multicolumn{6}{|c|}{ Progression-Free Survival } & \multicolumn{6}{|c|}{ Overall Survival } \\
\hline & HR & $95 \% \mathrm{CI}$ & $P$ & $\begin{array}{l}\text { HR for } \\
\text { CTC } \\
\text { trend* }\end{array}$ & $95 \% \mathrm{CI}$ & $P$ & HR & $95 \% \mathrm{CI}$ & $P$ & $\begin{array}{l}\text { HR for } \\
\text { CTC } \\
\text { trend* }\end{array}$ & $95 \% \mathrm{CI}$ & $P$ \\
\hline $\begin{array}{l}\text { Liver } \\
\text { metastases }\end{array}$ & 2.01 & $0.54-7.40$ & 0.2967 & 2.95 & $1.01-7.89$ & 0.0314 & 4.10 & $0.71-23.76$ & 0.1156 & 3.71 & $1.17-11.71$ & 0.0255 \\
\hline $\begin{array}{l}\text { MSKCC } \\
\text { score }\end{array}$ & 3.19 & $1.12-9.10$ & 0.0306 & 3.56 & $1.29-9.81$ & 0.0140 & 3.20 & $1.00-10.28$ & 0.0509 & 3.75 & $1.17-11.97$ & 0.0255 \\
\hline $\begin{array}{l}\text { RECIST } \\
\text { response }\end{array}$ & 47.47 & $3.77-597.85$ & 0.0028 & 2.95 & $1.02-8.56$ & 0.0464 & 2.17 & $0.42-11.28$ & 0.3590 & 2.84 & $0.80-10.07$ & 0.1057 \\
\hline
\end{tabular}

Abbreviations: CI: confidence interval; CTC: circulating tumor cell; HR: hazard ratio; RECIST: Response Evaluation Criteria in Solid Tumors. *Split in favorable (-/-, +/- and -/+) and unfavorable (+/+) groups based on $\mathrm{T}_{0}$ and $\mathrm{T}_{2}$ assessments.

CTC detection, adapted for UC patients, at our laboratory. Despite the limited sample size, we were able to find an association between patient outcomes and CTC changes early during first-line MVAC chemotherapy. Indeed an unfavorable CTC trend not only identified patients with a remarkably short PFS and OS, but also resulted to add information to well-established prognostic factors. Our results represent therefore a first step toward clinical validation, despite many possible limitations.

Being a pilot study in nature, the number of enrolled patients prevented us from better stratifying 
patients according to CTC trend. Whereas the allocation in the unfavorable group of patients with persistently CTC positive blood samples between $\mathrm{T}_{0}$ and $T_{2}$ is straightforward, inclusion of patients with negative baseline CTC and positive CTCs at $\mathrm{T}_{2}$ in the favorable group could appear counterintuitive. However, considering that at $\mathrm{T}_{2}$ almost two thirds of patients were defined as CTC positive, a possible interference of treatment on CTC release cannot be ruled out. In a recent publication, Martin et al. [29] reviewed clinical data suggesting that, although in general high numbers of CTCs are associated with bad prognosis, mobilization of CTC induced by treatment is possible and not necessarily associated with an adverse effect. For such a reason, patients who were defined as CTC-negative at baseline, but who switched to positive CTC, were included in the favorable group. Only the analysis of a higher number of patients will allow understanding if such speculation is correct; alternatively in the future the CTC assay could be modified to include a biomarker for apoptosis similarly to what has been done with the CellSearch ${ }^{\circledR}$ approach in other tumor types [30, 31].

Some other important limitations should be acknowledged in the present study. First, the small number of patients might have affected the reliability of regression analyses, and for this reason we evaluated the contribution of CTC trend to clinical outcomes adjusted for one clinical factor each time. Second, it is possible that the bivariate model did not account for inherent selection biases resulting from the long period of enrollment. However, although patient characteristics were consistent with those of first-line metastatic patients, almost all MVACtreated patients at our center were included (only 12 patients who received 1 cycle only due to the development of intolerable side effects were excluded) and the chemotherapy regimen was homogeneous as already reported [32]. Furthermore, quality indicators of the present cohort were the detrimental prognostic significance of liver metastases, MSKCC score and RECIST response. Third, given the exploratory nature of our study, which represents a pilot study exploiting the feasibility of an alternative CTC detection method for predicting clinical outcome, a generalization of results is impossible thus far.

In general, the identification of novel and validated prognostic factors in metastatic UC patients, mainly if they can be used early in the treatment course, is of paramount importance both in the daily practice and in the context of clinical trials. In daily clinical practice, based on the recent developments of immunotherapy in the salvage setting, new active drugs may be offered to those patients for whom a biomarker is able to predict chemoresistance or poor prognosis early after initiation of conventional therapy, whereas in a clinical trial new drugs or combination therapies can be investigated after few cycles of standard chemotherapy focusing on poor prognosis patients.

A similar objective did characterize another study that was conducted at our center with the use of early ${ }^{18}$ fluorodeoxyglucose (FDG) positron emission tomography after 2 cycles of first-line cisplatin-based chemotherapy (PET-2) in patients with metastatic UC. In 31 eligible patients, early variations in tumor FDG avidity at PET-2 were independently associated with PFS but not with OS [33]. Thus it is possible to hypothesize that the analysis of early CTC changes might result in enhancing imaging assessments and early predicting the outcome of patients, but this is presently only a hypothesis which deserves confirmation.

Most studies addressing CTC as potential biomarker in UC have used the CellSearch ${ }^{\circledR}$ platform [12], which has been approved by the FDA only for guiding treatment in metastatic breast, prostate and colon cancer. Different technical approaches like ours have been limitedly used. A recent study, which employed the IsoFlux test in comparison to CellSearch $^{\circledR}$ in the neoadjuvant and metastatic settings [23] reported that baseline CTC levels were better predictors of pathologic stage compared to CTC evaluated after one cycle of chemotherapy. The dynamic evaluation of CTC was not reported and a direct comparison with our data is prevented by the absence of clinical outcome data in the metastatic setting. Interestingly, the study by Alva et al. [23] reports preliminary data on the possibility to perform a sensitive next generation sequencing on CTCs which might detect clinically useful genomic alterations.

Indeed, for an effective translational research, CTC molecular characterization as well as circulating cell-free DNA may be ideal tools to non-invasively identify potentially "actionable" tumor alterations, ultimately leading to expedite precision therapy in "basket" and "umbrella" studies. Preliminary findings from such studies have been recently provided, showing that molecular analyses may be also useful in monitoring the tumor burden during treatment [34]. Of course, relevant pending issues are represented by the comparison of molecular profiling of CTCs or cell-free tumor DNA from liquid biopsies with that obtained from the primary tumor, the dynamic changes of such molecular alterations, hopefully able to capture information on disease evolution, and 
the development of reliable and robust molecular diagnostic and predictive tools. CTCs, as well as other components of liquid biopsies, have the potential to provide extraordinary information to improve patient's management.

The rarity of CTCs and their marked plasticity pose technical difficulties that still limit their clinical validity. Compared to classical EpCAM-based CTC enrichments methods [12] our approach presents the advantage of capturing also those CTCs which do not express epithelial antigens, thanks to the binding of an anti ERBB2 antibody linked the immunomagnetic beads used for CTC-enrichments, and of identifying CTCs not strictly based on their expression of epithelial genes only. In other clinical settings this strategy contributed to increase CTC positivity [24], but in UC no direct evidences are available since matched methodological comparisons were not performed on the same samples.

In conclusion, we propose an original method of assessing positivity and analyzing changes of CTC in patients with metastatic UC receiving first-line MVAC chemotherapy. Our study showed a significant association of CTC changes with clinical outcome; in particular, patients with persistently positive CTC after 2 cycles of MVAC had significantly worse PFS and OS. Pending validation of reproducibility and reliability of CTC results, as well as the clinical validity of such an association compared to standard radiologic assessments, these findings might help physicians improving patient prognostication, optimizing the administration of standard chemotherapy options, and designing clinical trials of sequential first-line therapies.

\section{ACKNOWLEDGMENTS}

We thank Dr. Silvia Veneroni and the personnel of the Biobank of Fondazione IRCCS Istituto Nazionale dei Tumori for collecting and providing blood specimens.

\section{CONFLICT OF INTEREST}

All authors have no conflict of interests to disclose.

\section{FUNDING}

This work was supported in part by Italian Ministry of Health, by funds obtained through an Italian law that allows taxpayers to allocate 0.5 percent share of their income tax contribution to a research Institution of their choice and by a FIRC (Fondazione Italiana per la Ricerca sul Cancro) fellowship to E.F.

\section{SUPPLEMENTARY MATERIAL}

The supplementary tables are available in the electronic version of this article: http://dx.doi.org/ 10.3233/BLC-160069.

\section{REFERENCES}

[1] Kamat AM, Hahn NM, Efstathiou JA, Lerner SP, Malmstrom PU, Choi W, Guo CC, Lotan Y, Kassouf W. Bladder cancer. Lancet 2016. pii: S0140-6736(16)30512-8. doi: 10.1016/S0140-6736(16)30512-8. [Epub ahead of print].

[2] Rosenberg JE, Hoffman-Censits J, Powles T, van der Heijden MS, Balar AV, Necchi A, Dawson N, O’Donnell PH, Balmanoukian A, Loriot Y, Srinivas S, Retz MM, Grivas , Joseph RW, Galsky MD, Fleming MT, Petrylak DP, Perez-Gracia JL, Burris HA, Castellano D, Canil C, Bellmunt J, Bajorin D, Nickles D, Bourgon R, Frampton GM, Cui N, Mariathasan S, Abidoye O, Fine GD, Dreicer R. Atezolizumab in patients with locally advanced and metastatic urothelial carcinoma who have progressed following treatment with platinum-based chemotherapy: A single-arm, multicentre, phase 2 trial. Lancet 2016;387: 1909-20.

[3] Massard C, Gordon MS, Sharma S, Rafii S, Wainberg ZA, Luke J, Curiel TJ, Colon-Otero G, Hamid O, Sanborn RE, O'Donnell PH, Drakaki A,Tan W, Kurland JF, Rebelatto MC, Jin X, Blake-Haskins JA, Gupta A, Segal NH. Safety and Efficacy of Durvalumab (MEDI4736), an AntiProgrammed Cell Death Ligand-1 Immune Checkpoint Inhibitor, in Patients With Advanced Urothelial Bladder Cancer. J Clin Oncol 2016;34:3119-25.

[4] Small AC, Gong Y, Oh WK, Hall SJ, van Rijn CJ, Galsky MD. The emerging role of circulating tumor cell detection in genitourinary cancer. J Urol 2012;188:21-6.

[5] Gudemann CJ, Weitz J, Kienie P, Lacroix J, Wiesel MJ, Soder M, Benner A, Staehler G, Doeberitz MV. Detection of hematogenous micrometastasis in patients with transitional cell carcinoma. J Urol 2000;164:532-6.

[6] Gazzaniga P, Gandini O, Giuliani L, Magnanti M, Gradilone A, Silvestri I, Gianni W, Gallucci M, Frati L, Aglianò AM. Detection of epidermal growth factor receptor mRNA in peripheral blood: A new marker of circulating neoplastic cells in bladder cancer patients. Clin Cancer Res 2001;7:577-83

[7] Retz M, Lehmann J, Roder C, Weichert-Jacobsen K, Loch T, Romahn E, Kalthoff H, Stockle M. Cytokeratin-20 reversetranscriptase polymerase chain reaction as a new tool for the detection of circulating tumor cells in peripheral blood and bone marrow of bladder cancer patients. Eur Urol 2001;39:507-15.

[8] Osman I, Kang M, Lee A, Deng FM, Polsky D, Mikhail M, Chang C, David DA, Mitra N, Wu XR, Sun TT, Bajorin DF. Detection of circulating cancer cells expressing uroplakins and epidermal growth factor receptor in bladder cancer patients. Int J Cancer 2004;111:580-4.

[9] Kinjo M, Okegawa T, Horie S, Nutahara K, Higashihara E. Detection of circulating MUC7-positive cells by reverse 
transcription-polymerase chain reaction in bladder cancer patients. Int J Urol 2004;11:38-43.

[10] Gazzaniga P, Nofroni I, Gandini O, Silvestri I, Frati L, Aglianò AM, Gradilone A. Tenascin $\mathrm{C}$ and epidermal growth factor receptor as markers of circulating tumoral cells in bladder and colon cancer. Oncol Rep 2005;14: 1199-1202.

[11] Leotsakos I, Dimopoulos P, Gkioka E, Msaouel P, Nezos A, Stravodimos KG, Koutsilieris M, Constantinides CA. Detection of circulating tumor cells in bladder cancer using multiplex PCR assays. Anticancer Res 2014;34:7415-24.

[12] Msaouel P, Koutsilieris M. Diagnostic value of circulating tumor cell detection in bladder and urothelial cancer: Systematic review and meta-analysis. BMC Cancer 2011;11:336.

[13] Naoe M, Ogawa Y, Morita J, Omori K, Takeshita K, Shichijyo T, Okumura T, Igarashi A, Yanaihara A, Iwamoto S, Fukagai T, Miyazaki A, Yoshida H. Detection of circulating urothelial cancer cells in the blood using the CellSearch System. Cancer 2007;109:1439-45.

[14] Karl A, Tritschler S, Hofmann S, Stief CG, Schindlbeck C. Perioperative search for circulating tumor cells in patients undergoing radical cystectomy for bladder cancer. Eur J Med Res 2009;14:487-90.

[15] Gallagher DJ, Milowsky MI, Ishill N, Trout A, Boyle MG, Riches J, Fleisher M, Bajorin DF. Detection of circulating tumor cells in patients with urothelial cancer. Ann Oncol 2009;20:305-8.

[16] Okegawa T, Hayashi K, Hara H, Nutahara K, Higashihara E. Immunomagnetic quantification of circulating tumor cells in patients with urothelial cancer. Int J Urol 2010;17: 254-8.

[17] Flaig TW, Wilson S, van Bokhoven A, Varella-Garcia M, Wolfe P, Maroni P, Genova EE, Morales D, Lucia MS. Detection of circulating tumor cells in metastatic and clinically localized urothelial carcinoma. Urology 2011;78:863-7.

[18] Rink M, Chun FK, Dahlem R, Soave A, Minner S, Hansen J, Stoupiec M, Coith C, Kluth LA, Ahyai SA, Friedrich MG, Shariat SF, Fisch M, Pantel K, Riethdorf S. Prognostic role and HER 2 expression of circulating tumor cells in peripheral blood of patients prior to radical cystectomy: A prospective study. Eur Urol 2012;61:810-7.

[19] Gazzaniga P, Gradilone A, de Berardinis E, Busetto GM, Raimondi C, Gandini O, Nicolazzo C, Petracca A, Vincenzi B, Farcomeni A, Gentile V, Cortesi E, Frati L. Prognostic value of circulating tumor cells in nonmuscle invasive bladder cancer: A CellSearch analysis. Ann Oncol 2012;23:2352-6.

[20] Gazzaniga P, de Berardinis E, Raimondi C, Gradilone A, Busetto GM, De Falco E, Nicolazzo C, Giovannone R, Gentile V, Cortesi E, Pantel K. Circulating tumor cells detection has independent prognostic impact in high-risk non-muscle invasive bladder cancer. Int J Cancer 2014; 135-1978-82.

[21] Rink M, Chun FK, Minner S, Friedrich M, Mauermann O, Heinzer H, Huland H, Fisch M, Pantel K, Riethdorf S. Detection of circulating tumour cells in peripheral blood of patients with advanced non-metastatic bladder cancer. BJU Int 2011;107:1668-75.

[22] Gradilone A, Petracca A, Nicolazzo C, Gianni W, Cortesi E, Naso G, Vincenzi B, Cristini C, De Berardinis E, Di Silverio F, Aglianò AM, Gazzaniga P. Prognostic significance of survivin-expressing circulating tumour cells in T1G3 bladder cancer. BJU Int 2010;106:710-5.
[23] Alva A, Friedlander T, Clark M, Huebner T, Daignault S, Hussain M, Lee C, Hafez K, Hollenbeck B, Weizer A, Premasekharan G, Tran T, Fu C, Ionescu-Zanetti C, Schwartz M, Fan A, Paris P. Circulating tumor cells as potential biomarkers in bladder cancer. J Urol 2015;194:790-8.

[24] Fina E, Reduzzi C, Motta R, Di Cosimo S, Bianchi G, Martinetti A, Wechsler J, Cappelletti V, Daidone MG. Did circulating tumor cells tell us all they could? The missed circulating tumor cell message in breast cancer. Int J Biol Markers 2015;30:429-33.

[25] Eisenhauer EA, Therasse P, Bogaerts J, Schwartz LH, Sargent D, Ford R, Dancey J, Arbuck S, Gwyther S, Mooney M, Rubinstein L, Shankar L, Dodd L, Kaplan R, Lacombe D, Verweij J. New response evaluation criteria in solid tumours: Revised RECIST guideline (version 1.1). Eur J Cancer 2009;45:228-47.

[26] McShane LM, Altman DG, Sauerbrei W, Taube SE, Gion M, Clark GM. REporting recommendations for tumour MARKer prognostic studies (REMARK). Br J Cancer 2005;93:387-91.

[27] Piantadosi S. Translational clinical trials: An entropy-based approach to sample size. Clin Trials 2005;2:182.

[28] Bajorin DF, Dodd PM, Mazumdar M, Fazzari M, McCaffrey JA, Scher HI, Herr H, Higgins G, Boyle MG. Long-term survival in metastatic transitional-cell carcinoma and prognostic factors predicting outcome of therapy. J Clin Oncol 1999; 17:3173-81.

[29] Martin OA, Anderson RL, Narayan K, MacManus MP. Does the mobilization of circulating tumour cells during cancer therapy cause metastasis? Nat Rev Clin Oncol 2016; [Epub ahead of print]

[30] Rossi E, Basso U, Celadin R, Zilio F, Pucciarelli S, Aieta M, Barile C, Sava T, Bonciarelli G, Tumolo S, Ghiotto C, Magro C, Jirillo A, Indraccolo S, Amadori A, Zamarchi R. M30 neoepitope expression in epithelial cancer: Quantification of apoptosis in circulating tumor cells by CellSearch analysis. Clin Cancer Res 2010;16:5233-43.

[31] Rossi E, Fassan M, Aieta M, Zilio F, Celadin R, Borin M, Grassi A, Troiani L, Basso U, Barile C, Sava T, Lanza C, Miatello L, Jirillo A, Rugge M, Indraccolo S, Cristofanilli M, Amadori A, Zamarchi R. Dynamic changes of live/apoptotic circulating tumour cells as predictive marker of response to sunitinib in metastatic renal cancer. $\mathrm{Br} \mathrm{J} \mathrm{Can-}$ cer 2012;107:1286-94.

[32] Necchi A, Mariani L, Giannatempo P, Raggi D, Farè E, Nicolai N, Piva L, Biasoni D, Catanzaro M, Torelli T, Stagni S, Maffezzini M, Pizzocaro G, De Braud FG, Gianni AM, Salvioni R. Long-term efficacy and safety outcomes of modified (simplified) MVAC (methotrexate/vinblastine/doxorubicin/cisplatin) as frontline therapy for unresectable or metastatic urothelial cancer. Clin Genitourin Cancer 2014;12:203-9.

[33] Giannatempo P, Alessi A, Miceli R, Raggi D, Farè E, Nicolai N, Serafini G, Padovano B, Piva L, Biasoni D, Torelli T, Catanzaro M, Stagni S, Maffezzini M, Mariani L, Gianni AM, Sonpavde G, Salvioni R, Necchi A, Crippa F. Interim fluorine-18 fluorodeoxyglucose positron emission tomography for early metabolic assessment of therapeutic response to chemotherapy for metastatic transitional cell carcinoma. Clin Genitourin Cancer 2014;12:433-9.

[34] Sonpavde G, Nagy RJ, Apolo AB, Agarwal N, Pal SK, Grivas P, Vaishampayan UN, Lanman RB, Talasaz AA. Circulating cell-free DNA profiling of patients with advanced urothelial carcinoma. J Clin Oncol 2016;34(suppl 2S; abstr 358). 